\title{
AS ETIMOLOGIAS DE ISIDORO DE SEVILHA
}

\section{Izidoro Blikstein}

Um exame inadvertido das explicações etimológicas em Eymologiarum siue Originum (1) pode levar-nos a críticas semelhantes às que se fizeram às etimologias da parte central do célebre diálogo de Platão, o Crátilo. Com efeito, no Livro $X$, por exemplo, em que Santo Isidoro se propõe a esclarecer a origem de alguns nomes - atitude claramente "etimológica" ("Origo quorundam nominum, id est unde ueniant. " $X, 1)$ - há interpretações que podem surpreender um estudioso moderno: amicus seria o mesmo que animi custos, "guarda da alma", e proviria de hamus, "gancho, anzol", por estabelecer o elo do amor $(X, 4-5)$; gloriosus viria de claritas com troca de $c$ por $g(X, 112)$; mendicus de minus habet ou de manu dicere, (pois o mendigo não poderia falar e sim estender a mão para obter a esmola, $X, 175)$; uir de uirtus $(\mathrm{X}, 274)(2)$ etc. Pois bem, seria um erro de perspectiva zombar de tais interpretações e vale, para a obra de Santo Isidoro, a observação de V. Goldschmidt acerca do Crátilo: " . uma vasta enciclopédia de teorias teológicas, cosmológicas e morais." (3); aliás, é bom lembrar que, a exemplo de Platão, o Bispo de Sevilha foi, antes de tudo, um filósofo de seu tempo. E preciso, pois, "reler" sua obra, sem levar em conta as etimologias ingênuas ou inexatas, mas extraindo inúmeras informações úteis para a lingüística moderna. Com razão observa Montero Díaz:

Las ironías que ciertos comentaristas han hecho sobre estos errores isidorianos responden a una crítica superficial, impresionista y desorbitada. Juzgar las derivaciones isidorianas con arreglo a la filología de nuestra época es una tarea de espíritus ápteros, carentes de sentido histórico. En los viente libros de San Isidoro hay que buscar: el genio compilador, la original integración del sistema

\footnotetext{
(1) - Isidoro de Servilha - Etymologyarum siue Originum - Oxford University Press, 1911.

(2) - A palavra uir, em $X I, 2,17$, é ligada a uis, o que é correto etimolo. gicamente. 1940.

(3) - Goldschmidt, V - Essai sur le "Cratyle" - Paris, Champion,
} 
en un método unitario, la salvación de noticias e informes concretos, el intento de armonizar el método de clasificación con el etimoló. gico"

Santo Isidoro, que viveu de 560 a 636, situava-se entre "los resultados de un período cultural que expiraba y el alba de una nueva edad." (5) As Etimologias constituem, então, uma alentada enciclopédia em que o Autor não recua diante de assunto algum: Gramática, Retórica, Dialética, Aritmética, Geometria, Música, Astronomia, Medicina, Direito, Teologia, Política, Zoologia, Geografia, Mineralogia, Agricultura etc. Se examinarmos atentamente a organização da obra, já é possível divisar algo bem original sob o ponto de vista lingüístico: trata-se de uma repartição em verdadeiros campos lexicais e semânticos e uma "leitura" semiológica traria à tona muitos elementos para a compreensão da cultura da época. O já citado Livro $X$, por exemplo, compõe-se de 282 parágrafos com aproximadamente 600 cabeças de verbetes, cuja etimologia propriamente nem sempre é apresentada, mas explicações semânticas de caráter bem genérico ligadas às concepções ético-religiosas de Santo Isidoro: amargo é um nome extraído do próprio sabor e qualifica o homem áspero que não sabe convidar docemente sua companhia ("Amarus a sapore translatum nomen habet. Est enin insuauis, nec nouit quemquam ad consortium suum aliqua invitare dulcedine", $X, 10)$ adúltero é o violador do pudor marital por ter manchado o leito alheio ("Adulter, violator maritalis pudoris, e o quod alterius torum polluat, $X, 10$ ), bonus "bom" parece provir de uenustate corporis, isto é, a beleza do corpo, que passa depois para a alma ("Bonus a uenustate corporis creditur dictus: postea et ad aninum translatum nomen", $X, 23$ ), casto era nome dado aos castrados e depois àqueles que ofereciam perpétua abstinência da sensualidade ("Castus primum a castratione nuncupatus: postea placuit ueteribus etiam eos sic nominari qui perpetuam libidinis abstinentiam pollicebantur, $X, 33$ ), uanus "vão" tem sua etimologia de Uenus, significando também vão, vazio, falso porque desaparece, sem deixar lembrança ("Uanus a Uenere etymologiam trahit. Item uanus inanis, falsus, eo quod memoria euanescat", $X, 280$ ) etc.

Pelos exemplos arrolados, evidencia-se a concepção etimológica de Santo Isidoro: a Etimologia é muito menos um fim em si mesma do que um meio de investigação semântico-didática das palavras, com objetivos ético-religiosos. Nessas condições, houve aproximações artificiais de significantes a fim de se criar, entre os significados, um liame útil e coerente com a ideologia da época. O exemplo acima

(4) - San Isidro de Servilha - Etimologias - Madrid, Editorial Cat6. lica, 1951, p. 20.

(5) - Id., ibid. 
citado, uanus a partir de Uenus, é bem eloqüente. Mas o próprio Santo Isidoro se expressa claramente sobre a utilidade e importância da Etimologia, com reflexões bem originais. Começa por definir a Etimologia como a origem das palavras, lembrando que através dela chegaremos a conhecer a força das palavras:

"Etymologia est origo uocabulorum, cum uis uerbi uel nominis per interpretatione colligitur". $(I, 291)$

Avulta, a seguir, o valor epistemológico da Etimologia, pois é mais fácil o conhecimento do objeto, se conhecemos a etimologia de seu nome:

\footnotetext{
"Omnis enim rei inspectio etymologia cognita planior est". $(I, 29,2)$
}

Não deixa de haver aqui a identificação de referente e referência. E na sequiência destas considerações que se encontra uma sábia e avançada reflexão acerca do problema central da Etimologia, ou seja, a relação motivada ou arbitrária entre significante e significado; com efeito, Santo Isidoro pondera que nem todas as coisas possuem nomes impostos pelos antigos conforme a natureza, pois alguns nomes foram dados conforme "à vontade", arbitrariamente (placitum):

"Non autem omnia a ueteribus secudum naturam inposita sunt, sed quaedam et secundum placitum..." $(I, 29,2)$

Trata-se de um ponto de vista realista no que concerne às possibilidades e limites da investigação etimológica e é notável como Santo Isidoro situa com justeza a problemática da Etimologia, ao observar que, pela "arbitrariedade" (ele emprega mesmo o termo arbitrium!) com que alguns nomes foram atribuídos às coisas, nem sempre é possível chegar à sua origem:

"Hinc est quod omnium nominum etymologiae non reperiuntur, quia quaedam non secundum qualitatem, qua genita sunt, sed iuxta arbitrium humanae uoluntatis uocabula acceperunt" $(I, 29,2)$

Da constatação de que as palavras podem ter uma origem natural ou convencional o Autor extrai uma metodologia para investigação etimológica com o estabelecimento de "regras": o etimologista pode determinar se a relação significante/significado (utilizando, é claro, a moderna terminologia) procede de uma causa (Reges vem de rectus agens, por agir retamente), origem (homo de humus, porque vem da terra), oposição (lutum de lauans, sendo que o lodo não é limpo), derivação (prudens de prudentia), imitação dos sons (garrulus 'tagarela" imitando a garrulitas "tagarelice"), origem grega (como do- 
mus e silua), origem ligada a lugares, cidades e rios ou origem estrangeira (barbara nomina) cuja etimologia é difícil determinar (" . . origo eorum uix cernitur."):

"Sunt autem etymologiae nominum aut ex causa datae, ut 'reges' a recte agendo, aut ex origine, ut 'homo', quia sit ex humo, autex contrariis ut a lauando 'lutum', dum lutum non sit mundum, et 'lucus'; quia umbra opacus parum luceat. Quaedam etiam facta sunt ex hominum deriuatione, ut a prudentia 'prudens'; quaedam etiam ex uocibus, ut a garrulitate 'garrulus'; quaedam ex Graeca etymologia orta et declinata sunt in Latinum, ut 'silua', 'domus'. Alia quoque ex nominibus locorum, urbium, uel fluminum traxerunt uocabula. Multa etiam ex diuersarum gentium sermone uocantur. Unde et origo eorum uix cernitur. Sunt enim pleraque barbara nomina et incognita Latinis et Graecis" ( $I, 29-3-4-5)$

Não me parece muito proveitoso nem justo ficar criticando as inexatidões da exemplificação (lutum de lauans, prudens de prudentia origem de domus e silua) (6), com a vantagem de 1.400 anos de estudos, cultura e métodos amontoados e acumulados depois de Santo Isidoro! Mais interessante será, sem dúvida, tentar detectar, nas considerações acima, o itinerário metodológico do Autor, de que se podem extrair algumas reflexões instrutivas para a história das idéias lingǘsticas. Eis algumas:

1) Santo Isidoro procede com grande acerto, ao formular "regras" de investigação etimológica depois de determinar a dupla natureza das palavras (natural e convencional);

2) as "regras" de causa, origem e oposiçāo, traduzidas para a Lingüística moderna, representam preocupaçōes da chamada "etimologia externa", segundo P. Guiraud (7);

3) as "regras" da derivação e imitação de sons, guardades as proporções, estão na ordem do dia: a derivação lembra as relações paradigmáticas de Saussure ou, mais recentemente, a idéia de P. Guiraud, para quem "toda criação verbal se efetua a partir de um modelo" (8), e a imitação de sons é uma das investigações

(6) - Cf. Einout, A. e Meillet, A. - Dicionnaire étymologique de la langue latine - Paris, Klincksieck, 1967, pp. 182, 372, 541 e 626, s.v.

(7) - Guiraud, P. - L'étymologie - Paris, P.U.F., 1964, pp. 88-89.

(8) - Id., p. 45 . 
centrais atualmente, desde M. Grammont (9) a P. Guiraud (10), M. Peterfalvi (11) etc.;

4) as "regras" referentes a nomes de origem gre ̧̧a e estrangeira lembram os estudos dialetológicos atu..1s acerca de empréstimos.

Mas é claro que há erros típicos da época, provenientes de uma concepção linguística que presidia a todas as filosofias de linguagem e representava, de certo modo, a ideologia científica da Idade Média; com efeito, todos os estudos estavam subordinados à Teologia (12) Daí decorria a preeminência do hebraico: “ por razões religiosas, consideravam efetivamente o hebraico, língua do Velho Testamento, como a língua primitiva a partir da qual convinha explicar todas as outras, seguindo nisso uma tradição cristã que parece remontar às especulaçōes do judaísmo alexandrino. ." (13); tal concepção apriorística (externa à Lingüística) determinaria também a valorização do grego e latim, línguas dos textos sagrados que eram. E o que se depreende do Livro IX em que Santo Isidoro trata de "línguas, povos, reinos, milícias" etc; diz ele que, antes de a soberba da Torre de Babel dividir a sociedade humana numa diversidade de línguas, não houve senão uma língua entre todos os povos, a saber, o hebraico:

\footnotetext{
"Nam priusquam superbia turis illius in diuersos signorum so. nos humanam diuidiret societatem, una omium nationum lingua fuit, quae Hebraea vocatur. " $(I X, I$ I)
}

Hebraico, grego e latim - como línguas sagradas - forneceriam a base para as interpretações linguísticas e, particularmente, etimológicas dos textos das Sagradas Escrituras:

"Tres sunt autem linguae sacrae: Hebraea, Graeca, Latina, quae toto orbe maxime excellunt. His enim tribus linguis super crucem Domini a Pilato fuit causa eius ecripta. Unde et proper obscuritatem sanctarum Scripturarum harum trium linguarum

(9) - Grammont, M. - Traité de phonétique - Paris, Delagrave, 1963 (Parte III: Phonétique impressive).

(10) - Guiraud, P - Structures étymologiques du lexique français Paris, Larousse, 1967.

(11) - Peterfalvi, J-M. - Recherches sur le symbolisme phonétique, Paris, CNRS, 1970.

(12) - Robins, R.H. - A Short History of Linguistics - Londres, Longmans, 1967, p. 69.

(13) - Leroy, M. - As Grandes Correntes da Lingüistica Moderna São Paulo, Cultrix, 1971, p. 22. 
cognitio necessaria est, ut ad alteram recurratur dum siquam dubitationem nominis uel interpretationis sermo unius linguae adtulerit" $(I X, I, 3-4)$

A interpretação da palavra homo ilustra perfeitamente a filosofia teológico-lingüística de Santo Isidoro: homo vem ex humo "da terra", porque foi feito de barro (segundo Gênesis, 2,7) passando a indicar depois, por extensão, o homem inteiro feito de corpo e alma:

"Homo dictus, quia ex humo est factus, sicut in Genesi dicitur $(2,7)$ : 'Et creauit Deus hominem de humo terrae' Abusiue autem pronuntiatur ex utraque substantia totus homo, id est ex societate animae et corporis" $(X I, I, 4)$

A mesma explicação aparece como exemplificação de uma das "regras" de etimologia no já citado trecho da p. 114:

"... ant ex origine, ut "homo", quia sit ex humo..."

e ainda no início do Livro dedicado à explicação de alguns nomes:

" .. sicut homo ab humo, unde proprie homo est appellatus". $(X, 1)$

A moderna Etimologia condena, nessa interpretação, o quia ou unde, isto é, a pretensa relação de origem ou causa entre nome e referente, mas não nega, antes afirma a origem comum de homo/hemo e humus, ligados a uma raiz indo-européia que significa "terra" (cf. védico ksah, grego $x \vartheta \hat{\imath} v$, $\chi \alpha \mu \alpha i$ ) (14) Por outro lado, até quase nossos dias, há quem seja tentado a aproximações entre o grupo indoeuropeu e o semítico, como, por exemplo, o eminente estudioso alemão H. Kiepert (1818-1899) que, em seu Handbuch der alte Geographie, § 413, nota 1, procura aproximar o nome de Córsega, Kúovos (que alguns procuram ligar à raiz de Ká@o "cabeça" / Ké@os "chifre") do hebraico qeren "chifre" (15)

Santo Isidoro não deve, pois, ser considerado tão estranho à Lingüística. Só mesmo no século XIX, com o comparatismo histórico, é que teremos uma visão mais esclarecedora do indo-europeu e da distribuição das línguas indo-européias; para o Filósofo de Sevilha, entretanto, havia uma nítida separação entre palavras de "origem grega" e as de "origem estrangeira" Isto também se deve à valorização do grego, como uma das línguas principais, ao lado do hebraico e latim.

(14) - Ernout - Meillet - op. cit., pp. 297, 298 e 302, s.v.

(15) - Apud Danielsson, O.A. - Grammatische und Etymologischen Studien, Upsala, 1888. 
Para terminar, um comentário sobre o Livro XI, em que Santo Isidoro trata de um campo semântico muito estudado pela linguíística moderna: as partes do corpo. O corpo humano é analisado em suas várias partes com uma minúcia admirável para a época: os cinco sentidos (uisus, auditus, odoratus, gustus, tactus), a cabeça e suas partes (caput, uortex, caluaria, capilli, tempora, facies, frons, oculi, nares, os, labia, lingua, dentes,), os vários membros (brachia, manus, digiti, femora, coxae, crura, pedes), e ainda o coração (cor), sangue, (sanguis) veias (uenae), intestinos (intestina), útero (uterum), a matrix (onde se engendra o feto), a uulua (que recebe o sêmen), urina, semen etc. O denominador comum de todas essas etimologias é sempre a concepção religiosa do ser humano; o corpo é interpretado, então, dentro da dualidade corpo / alma e o nome de cada parte explica-se por uma causalidade externa à Lingüística . Apesar disto, muita explicação desperta interesse pelo encanto poético:

"Uulua uocata quasi ualua, id est ianua uentris, uel quod semen recipiat, uel quod ex ea foetus procedat". $(X I, I, 137)$.

O curioso é que até agora não se determinou a origem certa de uulua (16) A área lexical referente a "cabeça" reflete, é claro, a ideologia do Bispo de Sevilha em suas explicações etimológicas; a cabeça (caput) é o centro do corpo, dos sentidos, da vida, enfim, e tudo tem início nela (capiunt initium), daí ser a mais pura representação da alma:

"Prima pars corporis caput; datumque illi hoc nomen eo quod sensus omnes et nerui inde initium capiant, atque ex eo omnis uigendi causa oriatur... Unde ipsius animae, quae consulit corpori, quodammodo personam gerit". $(X I, 1,25)$ (grifos meus).

Há um dado importante a ser extraído desta explicação; com efeito, é possível discernir nas entrelinhas um dos traços sêmicos do semema "cabeça": anterioridade/superatividade (para usar da terminologia de Greimas) (17). Ainda neste campo léxico, encontram-se tempora, facies, uultus e frons. Não falarei da fantasiosa interpretação de tempora (cabelos à esquerda e da direta da cabeça que têm a mobilidade dos tempos!), mas vale transcrever a distinção semântica estabelecida para os dois nomes do "rosto": facies (que vem de effigies!) indicaria a face externa, a fisionomia da pessoa e uultus (de uoluntas!) diria respeito ao estado psicológico, interior dos seres. $(X I, 1,34)$ Ora, no alentado e moderno Les dénominations du visage en français (18),

(16) - Ernout - Meillet - op. cit., pp. 751-752, s.v.

(17) - Greimas, A.J. - Semântica Estrutural - São Paulo, Cultrix, 1973, pp. 57-66.

(18) - Renson, J. - Les dénominations du visage en français et dans d'autres langues romanes, - Paris, Les Belles Lettres, 1962. 
a área semântica de "rosto" apresenta, entre outros, os traços sêmicos referentes à fisionomia interna e externa. Perdoemos as fantasias a Santo Isidoro!

Falta, evidentemente, um nexo estrutural a todas essas etimologias. Não há ainda noção de raiz, família de palavras ou evolução fonética. Trata-se, como já foi dito, de uma etimologia externa a serviço da concepção teológica do universo. Esparsamente, entretanto, pode-se colher um ou outro liame semântico e formal, como no caso de capitolium "capitel" que constitui "a cabeça da coluna":

$$
\begin{aligned}
& \text { "Capitolia dicta quod sint columnarum capita, sicut super } \\
& \text { collum capita" (XV, VIII, 15) }
\end{aligned}
$$

Já ceruix "nuca, pescoço" é ligada a cerebrum apenas por um liame semântico externo de causa (bem ao gosto de Santo Isidoro), embora haja também uma relação formal, pois ambos estão ligados à raiz

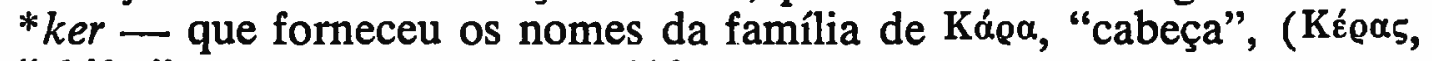
"chifre", cornū, ceruus etc.) (19)

"Ceruix autem uocata, quod per eam partem cerebrum ad medullam spinae dirigitur, quasi cerebri uia" $(X I, I, 61)$

Mas é bem percebida a derivação semântica e formal em ceruical (espécie de travesseiro, para a nuca ou pescoço):

$$
\begin{aligned}
& \text { "Ceruicalia autem eo quod ponantur sub ceruice uel cubito" } \\
& (X I X, X X V I, 4)
\end{aligned}
$$

Apesar de não perceber que cornū "chifre" seja da família de ceruix, o Autor divisa o mesmo traço sêmico ("ponta, extremidade") na utilização do referido termo em dois contextos diferentes; cornua pode indicar, por metáfora, as extremidades da antena do navio:

$$
\begin{aligned}
& \text { "Cornua extremae partes antemnarum sunt, dictae per tropum". } \\
& (X I X, I I, 7)
\end{aligned}
$$

ou, então, as alas recurvadas do exército:

$$
\begin{aligned}
& \text { "Cornua uocantur extremitates exercitus, quod intorta sint" } \\
& (I X, I I I, 63-64)
\end{aligned}
$$

A noção de "ponta, extremidade", ligada à de "dureza", é invocada para a explicação do termo cornum que indica justamente o corniso ou cerejeira silvestre, árvore "dura" de que se tiravam lanças (Vir-

(19) - Ernout-Meillet - op. cit., pp. 116, s.v. 
gílio endossa a explicação ao dizer que o cornum é bom para a guerra):

" .sed durum; unde et cornum appellatum est. Est autem arbor opta hastilibus: unde Vergilius (Georg., 2,448): Bona bello cornum" (XVII, VII, 16)

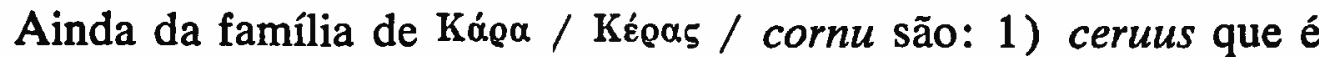
aproximado de cornua e do grego Képas (embora não fique claro, no texto, que sejam de uma mesma família):

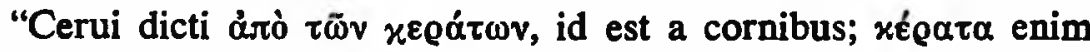
Graece cornua dicuntur"' $(X I I, I, 18)$

A aproximação correta não se deve a uma consciência da família etimológica, mas novamente, a uma relação externa; 2) rhinoceron, aproximado, por tradução, de cornu:

"Rhinoceron a Graecis uocatus. Latine interpretatur in nare cornu. Idem et monoceron, id est unicornus, eo quod unum cornu in media fronte habeat..." (XII, II, 12)

Poderia citar ainda coryza "coriza" relacionada à cabeça ("Coryza est quotiens infusio capitis. "IV,VII, 12), aproximação interessante, se fosse demonstrável a hipótese que liga xópusa, xópus, xé $\alpha_{5}$ à mesma raiz *ker -; Chantraine, recentemente, afastou tal possibilidade (20) E há também o caso de crapula, mal-estar proveniente da voracidade ("Crapula est inmoderata uoracitas, quasi cruda epula, cuius cruditate grauatur cor et stomachus indigestus efficitur", $X X, I I, 9)$ que mais recentemente foi aproximado de xoourá $\lambda \eta$, designando uma tonteira ou dor de cabeça proveniente de embriaguez (ressaca); neste caso, a noção de "cabeça" estaria contida em cra - ou

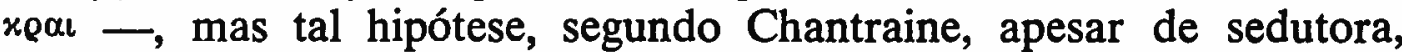
não tem fundamento (21).

Há algo irônico em tudo isso: muitos criticam as fantasias de Santo Isidoro, mas será que estamos tão adiante dele?! Quanta hipótese incerta, improvável, sem fundamento! Isto é tão verdadeiro que nossos melhores dicionários etimológicos são justamente aqueles que registram corajosamente "incerto", "desconhecido", "improvável", como o fazem Ernout-Meillet, Chantraine e outros. A virtude do moderno etimologista está em reconhecer suas limitações;

(20) - Chantraine, P. - Dictionnaire étymologique de la langue grecque - Paris, Klincksieck, 1970 - tomo II, pp. 568-569, s.v. 576, s.v.

(21) - Ernout-Meillet, op. cit., p. 147, s.v. e Chantraine, op. cit., p. 
talvez, por isto, é que ele só pode ostentar um título, no irônico dizer do Président de Brosses (22): o de ser julgado de modo pouco favorável pela maioria das pessoas.

(22) - Apud Guiraud, P. - L'étymologie - p. 1. 